\title{
Molecular Events Involved in Influenza A Virus-Induced Cell Death
}

\author{
Rui Gui ${ }^{1,2}$ and Quanjiao Chen ${ }^{1 *}$ \\ ${ }^{1}$ CAS Key Laboratory of Special Pathogens and Biosafety, Center for Biosafety Mega-Science, CAS Center for Influenza \\ Research and Early Warning, Wuhan Institute of Virology, Chinese Academy of Sciences, Wuhan, China, ${ }^{2}$ University \\ of Chinese Academy of Sciences, Beijing, China
}

Viral infection usually leads to cell death. Moderate cell death is a protective innate immune response. By contrast, excessive, uncontrolled cell death causes tissue destruction, cytokine storm, or even host death. Thus, the struggle between the host and virus determines whether the host survives. Influenza A virus (IAV) infection in humans can lead to unbridled hyper-inflammatory reactions and cause serious illnesses and even death. A full understanding of the molecular mechanisms and regulatory networks through which IAVs induce cell death could facilitate the development of more effective antiviral treatments. In this review, we discuss current progress in research on cell death induced by IAV infection and evaluate the role of cell death in IAV replication and disease prognosis.

OPEN ACCESS

Edited by:

Honglin Luo,

University of British Columbia,

Canada

Reviewed by:

Yasir Mohamud,

University of British Columbia,

Canada

Shinji Ohno,

University of the Ryukyus, Japan

*Correspondence:

Quanjiao Chen

chenqj@wh.iov.cn

Specialty section:

This article was submitted to

Virology,

a section of the journal

Frontiers in Microbiology

Received: 19 October 2021

Accepted: 29 November 2021

Published: 07 January 2022

Citation:

Gui R and Chen Q (2022)

Molecular Events Involved in Influenza

A Virus-Induced Cell Death.

Front. Microbiol. 12:797789.

doi: 10.3389/fmicb.2021.797789
Keywords: cell death, influenza A virus, apoptosis, necroptosis, pyroptosis, viral infection

\section{INTRODUCTION}

Apoptosis, necroptosis, and pyroptosis are the three main patterns of cell death in multicellular organisms, playing vital roles not only in embryonic development; normal tissue homeostasis; and diseases, such as atherosclerosis, cancer, and neurodegeneration, but also in defense reactions against infection (Bellamy et al., 1995; Galluzzi et al., 2008; Fuchs and Steller, 2011; Walsh, 2014; Jorgensen et al., 2017; Gao et al., 2018). The concept of apoptosis was proposed for the first time in 1972 (Kerr et al., 1972). Apoptosis can be activated by two distinct signaling pathways, namely, intrinsic (mitochondrial) and extrinsic (death receptor) pathways (Lowy, 2003). The term "necroptosis" was first used to describe necrotic cell death in 2005 (Degterev et al., 2005). In the next decade, several critical molecules, including receptor interacting protein kinase (RIPK) $1 / 3$ and mixed lineage kinase domain like pseudokinase (MLKL) were found to be involved in necroptosis (Holler et al., 2000; Degterev et al., 2005; Cho et al., 2009; He et al., 2009; Zhang et al., 2009; Murphy et al., 2013). Additionally, pyroptotic cell death was first observed in 1986, when a research team found that cultured primary mouse macrophages induced cell death and leakage of cell contents when treated with the lethal toxin anthrax (Friedlander, 1986). In subsequent decades, follow-up research showed that pyroptosis relies on a gasdermin family member to induce cell rupturing and release cellular contents (Kayagaki et al., 2015; Liu et al., 2016; Aglietti and Dueber, 2017; Shi et al., 2017). Although cross-talk exists between apoptosis, necroptosis, and pyroptosis, apoptosis has minimal impact on neighboring cells because it is a non-inflammatory type of cell death; this is the main difference between apoptosis, necroptosis, and pyroptosis. Moreover, in necroptosis and pyroptosis, the release of cellular contents is an intense trigger of innate and adaptive immune responses (Henson et al., 2001; van Delft et al., 2010; Wallach et al., 2016; Shi et al., 2017). 
Influenza A virus (IAV) is a negative-sense single-stranded RNA virus that is a member of the Orthomyxoviridae family (Yamauchi, 2020). IAV is among the most notorious respiratory diseases, causing almost 3-5 million cases of critical illness and approximately 250,000-500,000 deaths worldwide each year (Walsh, 2014; Hartmann et al., 2017; Doyon-Plourde et al., 2019). IAV mainly infects the airway epithelial cells, leading to inflammation and cell death, followed by respiratory tract damage, pneumonia, and even respiratory dysfunction or failure (Le Goffic et al., 2007; Cardani et al., 2017; Atkin-Smith et al., 2018). Severe IAV infection is always accompanied by hypercytokinemia, also known as cytokine storm, which is closely related to disease severity and could be a predictor of disease progression and mortality (De Jong et al., 2006; Guo et al., 2015; Zhang Y. et al., 2020). However, cell death and inflammation do not always harm the host; moderate cell death and inflammation can facilitate the elimination of viruses (Kuriakose et al., 2016; Zheng et al., 2020). Therefore, exploring the relative contribution of cell death and inflammation to suppression of viral replication and improvement of prognosis vs. disruption of host homeostasis and physical function, is particularly important for developing novel treatment strategies (Brandes et al., 2013).

In this review, we discuss the mechanisms of the three types of cell death (apoptosis, necroptosis, and pyroptosis) during IAV infection to address how IAV triggers and manipulates cell death and how these processes determine the final fates of viruses, cells, and hosts.

\section{APOPTOSIS DURING INFLUENZA A VIRUS INFECTION}

Characteristic morphological features of intrinsic apoptosis, including flowing nuclear and cytoplasmic condensation, fragmentation of cellular DNA and membrane blebbing with apoptotic body formation during IAV infection were observed in previous studies (Takizawa et al., 1993; Fesq et al., 1994; Hinshaw et al., 1994; Mori et al., 1995). However, the specific mechanisms through which IAV induces apoptosis and the roles of apoptosis in IAV infection remain unclear. In recent years, apoptosis has been documented as a cell defense strategy against invading viruses in most multi-cellular organisms (Robert et al., 2012). Unfortunately, in the battle between viruses and their hosts, viruses have also evolved the ability to subvert apoptosis in the host cells (Danthi, 2016; Orning et al., 2018). Thus, apoptosis has both positive and negative effects on the life cycle of IAV (Galluzzi et al., 2008). In general, early apoptosis reduces viral replication, whereas late apoptosis promotes the release and dissemination of progeny viruses (Zhou et al., 2017).

\section{INTRINSIC APOPTOSIS}

IAV primarily induces intrinsic apoptosis through some viral proteins and the IAV progeny ribonucleoprotein complex (vRNP) (Table 1). Research on apoptosis has revealed details of the mechanisms underlying IAV-induced apoptosis (Cardani et al., 2017; Zhou et al., 2017; Atkin-Smith et al., 2018).

These mechanisms may be classified into three types based on how viral proteins of IAV activate apoptosis. First, viral proteins interact with a host protein. Subsequently, mitochondrial membrane permeability is increased, which activates other specific signaling pathways to induce apoptosis (Chen et al., 2001). Second, vRNPs interact directly with DNA-dependent activator of interferon (IFN)-regulatory factor (DAI), which activates caspase- 8 and then caspase-3, to induce apoptosis (Thapa et al., 2016). Third, upon IAV infection, endoplasmic reticulum (ER) stress and autophagy are triggered, thereby inducing apoptosis (Frabutt et al., 2018; Yeganeh et al., 2018). Fourth, some viral proteins can regulate apoptosis directly; however, the details of this mechanism are still unclear (Schultz-Cherry et al., 2001).

The viral protein PB1-F2 encoded by $P B 1$, which is localized in the mitochondria of MDCK cells infected with IAV, has been shown to induce intrinsic apoptosis (type I) (Gibbs et al., 2003; Zamarin et al., 2005). In vitro, microinjection of PB1-F2 into MDCK cells causes its mitochondrial localization, which results in swelling and fragmentation, nuclear shrinkage, and cell death (Zamarin et al., 2005). In a previous study, the release of cytochrome $c$ tagged with green fluorescent protein (CcGFP) from mitochondria was observed using flow cytometry when HeLa cells that contained a fusion protein consisting of Cc-GFP overexpressed in the mitochondria were transfected with PB1-F2. The release of Cc-GFP from mitochondria was observed in about $55 \%$ of cells in the PB1-F2 treatment group, compared with only $7 \%$ in the control group (Chen et al., 2001). In addition, when PB1-F2 was co-transfected with the anti-apoptotic protein Bcl-2 in Cc-GFP HeLa cells, release of Cc-GFP was decreased. Moreover, PB1-F2 can interact with adenine nucleotide translocase 3 (ANT3) and voltagedependent anion-selective channel 1 (VDAC1), which are critical components of the pore complex on the mitochondrial membrane. When bongkrekic acid, a ANT3 inhibitor, was incubated with PB1-F2, apoptosis was also blocked partially (Figure 1; Zamarin et al., 2005).

In addition, the IAV nucleoprotein (NP), which is an essential part of the vRNP, also plays vital roles in promoting apoptosis and viral proliferation (Nailwal et al., 2015). NP induces apoptosis by hijacking host proteins such as clusterin precursor (CLU), RING finger protein 43 (RNF43), and apoptosis inhibitor 5 (API5). CLU was the first host protein identified, and has been shown to interact with NP to regulate apoptosis. CLU binds with Bax to inhibit the mitochondrial translocation of Bax and prevent apoptosis. However, when NP interacts with CLU, the interaction blocks the binding of CLU and Bax, thereby promoting apoptosis (Figure 1). Previous studies have evaluated the p53-Bax mitochondrial apoptosis network (McCurrach et al., 1997; Chipuk and Green, 2004; Chipuk et al., 2004; Ohtsuka et al., 2004) and shown that p53 is degraded by the host protein RNF43 through ubiquitination; however, ubiquitination is hampered when NP binds with RNF43, thereby promoting apoptosis (Figure 1; Nailwal et al., 2015). API5 is an anti-apoptotic protein whose mRNA and protein levels 
TABLE 1 | Viral proteins of IAV that are involved in cell death.

\begin{tabular}{|c|c|c|c|}
\hline IAV protein & Subtypes & Molecular mechanism & Types of death \\
\hline $\mathrm{HA}$ & $\mathrm{H} 1 \mathrm{~N} 1$ & $\begin{array}{l}\text { - HA promotes apoptosis by enhancing host cell endoplasmic reticulum } \\
\text { stress (Frabutt et al., 2018). } \\
\text { - Unknown (Hartmann et al., 2017). }\end{array}$ & $\begin{array}{l}\text { Apoptosis } \\
\text { Necroptosis }\end{array}$ \\
\hline NA & $\begin{array}{l}\mathrm{H} 1 \mathrm{~N} 1 \\
\mathrm{H} 3 \mathrm{~N} 2\end{array}$ & $\begin{array}{l}\text { - NA stimulates endoplasmic reticulum stress, enhancing apoptosis (Slaine } \\
\text { et al., 2021). } \\
\text {-NA interacts with CEACAM6 protein, which increases the tyrosine } \\
\text { phosphorylation of FAK, AKT, GSK3 } \beta \text {, and Bcl-2, and inhibits cell death } \\
\text { (Gaur et al., 2012). }\end{array}$ & Apoptosis \\
\hline NP & $\begin{array}{l}\mathrm{H} 1 \mathrm{~N} 1 \\
\mathrm{H} 1 \mathrm{~N} 1 \\
\mathrm{H} 3 \mathrm{~N} 2\end{array}$ & $\begin{array}{l}\text { - NP directly interacts with the anti-apoptotic protein CLU, which inhibits } \\
\text { apoptosis by interacting with Bax, thereby interfering with the function of } \\
\text { CLU (Tripathi et al., 2013). } \\
\text { - NP promotes apoptosis by down-regulating API5 expression; this } \\
\text { interferes with E2F1 recruitment to the Apaf-1 promoter, leading to } \\
\text { down-regulation of Apaf-1 and impairment of apoptosome formation } \\
\text { (Morris et al., 2006; Mayank et al., 2015). } \\
\text { - NP interacts with RNF43, which can inhibit apoptosis by interacting with } \\
\text { Bax and impairing RNF43 function (Nailwal et al., 2015). }\end{array}$ & Apoptosis \\
\hline NS1 & $\begin{array}{l}\mathrm{H} 5 \mathrm{~N} 1 \\
\mathrm{H} 1 \mathrm{~N} 1\end{array}$ & $\begin{array}{l}\text { - Unknown (Schultz-Cherry et al., 2001; Lam et al., 2008). } \\
\text { - NS1 interacts with MLKL to induce oligomerization and membrane } \\
\text { translocation (Gaba et al., 2019). }\end{array}$ & $\begin{array}{l}\text { Apoptosis } \\
\text { Necroptosis }\end{array}$ \\
\hline NS2 & - & - & - \\
\hline M1 & $\mathrm{H} 1 \mathrm{~N} 1$ & $\begin{array}{l}\text { - M1 directly interacts with Hsp70, which then interacts with Apaf-1 to } \\
\text { disrupt apoptosome formation (Halder et al., 2011). }\end{array}$ & Apoptosis \\
\hline M2 & $\mathrm{H} 1 \mathrm{~N} 1$ & $\begin{array}{l}\text { - M2 interacts with the ATG5/Beclin-1 complex to inhibit autophagosome } \\
\text { fusion, promoting apoptosis (Gannage et al., 2009). } \\
\text { - M2-mediated perturbation of ion concentrations triggers activation of the } \\
\text { NLRP3 inflammasome (Ichinohe et al., 2010). }\end{array}$ & $\begin{array}{l}\text { Apoptosis } \\
\text { Pyroptosis }\end{array}$ \\
\hline PB1-F2 & $\begin{array}{l}\mathrm{H} 3 \mathrm{~N} 2 \\
\mathrm{H} 1 \mathrm{Nl} \\
\mathrm{H} 1 \mathrm{~N} 1\end{array}$ & $\begin{array}{l}\text { - PB1-F2 activates the NLRP3-ASC inflammasome (McAuley et al., 2013). } \\
\text { - PB1-F2 localizes to the mitochondria and alters mitochondrial permeability } \\
\text { (Gibbs et al., 2003). }\end{array}$ & $\begin{array}{l}\text { Pyroptosis } \\
\text { Apoptosis }\end{array}$ \\
\hline PA-X & - & - & - \\
\hline PA & $\mathrm{H} 1 \mathrm{~N} 1$ & $\begin{array}{l}\text { - vRNPs are sensed by DAI/ZBP1, which then triggers the downstream cell } \\
\text { death signaling pathway (Kuriakose et al., 2016; Thapa et al., 2016). }\end{array}$ & Apoptosis \\
\hline PB1 & & & Necroptosis \\
\hline PB2 & & & Pyroptosis \\
\hline
\end{tabular}

are down-regulated when NP is overexpressed or when the cells were infected with IAV (Mayank et al., 2015). Further studies have demonstrated that NP promotes apoptosis by downregulating API5, thereby interfering with E2F1. This blocks recruitment of E2F1 to the apoptotic protease-activating factor1 (Apaf-1) promoter, resulting in downregulation of Apaf-1 and thereby impairing apoptosome formation (Figure 1; Mayank et al., 2015). Neuraminidase (NA) protein functions primarily to facilitate the release of progeny virions. However, a recent study showed that NA also interacts with carcinoembryonic antigen-related cell adhesion molecule 6 (CEACAM6) to increase the phosphorylation of $\mathrm{Src}, \mathrm{AKT}$, and $\mathrm{Bcl}-2$, resulting in inhibition of apoptosis and promotion of cell survival (Figure 1; Gaur et al., 2012).

The microenvironmental perturbations caused by IAV infection include autophagy and ER stress, both of which are implicated in IAV-induced apoptosis (Frabutt et al., 2018; Yeganeh et al., 2018). Both hemagglutinin (HA) which is responsible for viral attachment to cell-surface sialic acid residues and subsequent fusion of the viral and host cell membranes and NA proteins trigger the ER stress response
(Frabutt et al., 2018; Slaine et al., 2021). Upon IAV infection, the ER stress markers (transcription factor 6 (ATF6) and endoplasmic reticulum protein $57-\mathrm{kDa}$ (ERp57) are significantly upregulated compared with that in the control group, whereas RNAi knockdown of ATF6 and ERp57 reduces the activity of caspase-3 (Roberson et al., 2012). In addition to the ER stress pathway, autophagy is also implicated in IAV-induced apoptosis. One major characteristic of autophagy is the formation of autophagosomes, which capture cellular components, and fuse with lysosomes, where the cargo is degraded (Gannage et al., 2009; Maiuri et al., 2010). Upon IAV infection, autophagosomes accumulate, and the formation of autophagosome-lysosome complexes can be blocked by M2 ion channels, which function to facilitate fusion between the viral envelope and the endosomal membrane to mediate genome uncoating; these complexes the interact with ATG5/Beclin-1, enabling evasion of autophagymediated viral clearance, which significantly enhances apoptosis following IAV infection (Gannage et al., 2009).

The apoptosome consists of Apaf-1, Apaf-2 (Cyt c), Apaf-3 (caspase-9 precursor), and dATP. When Apaf-1 interacts with Apaf-3 through its N-terminal CARD domain in the presence 


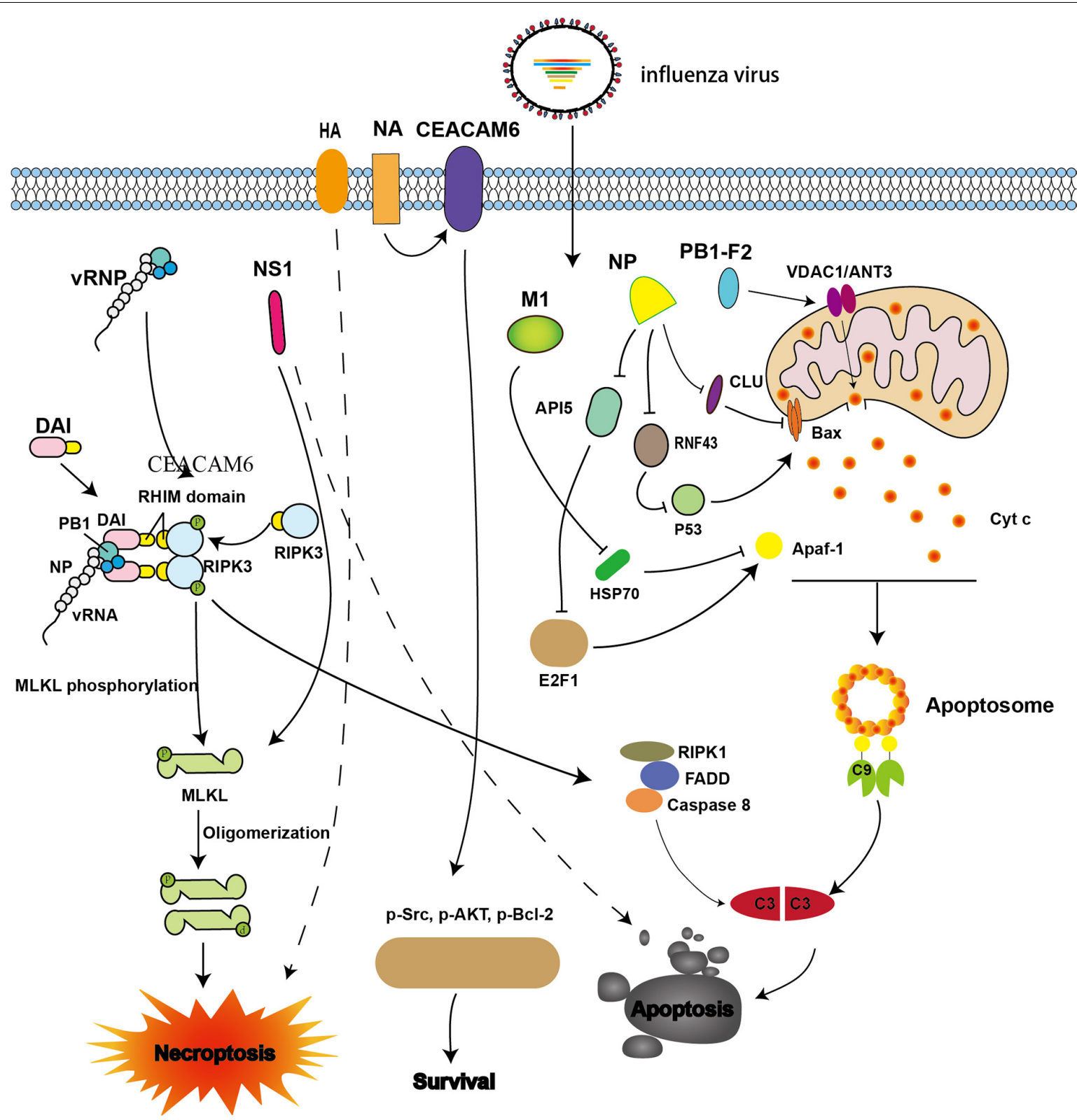

FIGURE 1 | Viral proteins involved in intrinsic apoptosis and necroptosis during influenza A virus (IAV) infection. The IAV progeny ribonucleoprotein complex (VRNP) is sensed by DAl via recruitment of RIPK3 to activate MLKL. NS1 directly interacts with MLKL and induces its oligomerization. NS1 also can induce apoptosis; however, the underlying mechanism is not well understood. NA interacts with CEACAM6 and increases the phosphorylation of Src, AKT, and Bcl-2, thereby inhibiting apoptosis. When M1 binds with Hsp70, apoptosome formation is blocked. When NP interacts with CLU and RNF43, its ability to resist apoptosis is weakened by interference with the mitochondrial translocation of Bax. NP also promotes apoptosis by down-regulating API5 expression, thereby inhibiting E2F1 recruitment to the Apaf-1 promoter. The expression of Apaf-1 is then blocked, and apoptosome formation is impaired. PB1-F2 interacts with ANT3 and VDAC1, resulting in increased permeability of the mitochondrial outer membrane and induction of cytochrome $\mathrm{c}$ release.

of Apaf-2 and dATP, pro-caspase- 9 is activated and converted to effector caspase-9, which initiates the caspase cascade (Liu et al., 1996; Li et al., 1997). Furthermore, Apaf-1 interacts with the C-terminal of heat shock protein 70 (Hsp70), which inhibits apoptosome formation and reduces apoptosis; however, M1 can bind with the substrate-binding domain of Hsp70 and interferes with the anti-apoptotic function of Hsp70 (Figure 1; Halder et al., 2011).
DAI (ZBP1/DLM-1) has been shown to act a cytoplasmic DNA sensor (Wang et al., 2008; Rebsamen et al., 2009; DeFilippis et al., 2010). In addition, upon IAV infection, pattern recognition receptors (PRRs) are also involved in the mechanism of cell death. In particular, DAI, which belongs to the cytosolic DNA sensor family, is one of the most important PRRs and, directly participates in IAV-induced cell death (here, we limit our discussion to its role in apoptosis). Recent studies have 
demonstrated that vRNPs with defective viral genomes are directly sensed by the $Z \alpha$ domains of DAI (Thapa et al., 2016; Kesavardhana et al., 2017; Wang et al., 2019; Zhang T. et al., 2020).

During IAV infection, DAI recruits RIPK3 to activate downstream signaling via its RIPK homotypic interaction motif (RHIM) domains (Thapa et al., 2016; Kesavardhana et al., 2017). The activation of caspase- 8 and caspase- 3 is abrogated in $\mathrm{DAI}^{-/-}$and $\mathrm{RIPK}^{-/-}$cells, thereby inhibiting apoptosis (Kuriakose et al., 2016). Accordingly, IAV may promote apoptosis through the DAI/RIPK3/caspase-8 axis (Figure 1).

Non-structural protein 1 (NS1), which is encoded by the IAV NS gene, can antagonize innate immunity, e.g., by suppressing IFN-I secretion, and promote viral replication. NS1 has also been shown to be involved in the regulation of apoptosis; however, the mechanism is still unclear (Schultz-Cherry et al., 2001; Zhirnov et al., 2002; Lam et al., 2008). A comparison of apoptosis in cultured cells infected with wild-type (WT) IAVs (A/PR/8/34) and recombinant viruses with a mutant NS1 gene (SchultzCherry et al., 2001) showed that typical apoptotic features, such as DNA fragmentation, were observed in WT IAVs, but not in mutant virus (Figure 1; Schultz-Cherry et al., 2001). Further studies are needed to assess the molecular mechanisms.

\section{EXTRINSIC APOPTOSIS}

In addition to intrinsic pathways, IAV can mediate apoptosis via extrinsic signaling. The extrinsic apoptosis pathway is mediated by specific cell surface death receptors belonging to the tumor necrotic factor (TNF) receptor (TNFR) family, namely, TNFR1, Fas, and TRAIL-R1/2 (Figure 2; Nagata, 1999; MacFarlane et al., 2005; Vanden Berghe et al., 2015). All of these receptors possess an intracellular death domain (DD), which can recruit downstream adaptor proteins to assemble a set of complexes. The complexes activate caspase- 8 and then induce apoptosis through a variety of homotypic interactions (Lee et al., 2012; Nair et al., 2014). These processes are tightly regulated and connected with necroptosis (Guo et al., 2015). TNFR1 plays a major role in mediating extrinsic apoptosis, and this process has been studied thoroughly. Here, we will use the TNRF1 pathway as an example to explain progress in studies of extrinsic apoptosis.

The binding of TNF $\alpha$ and TNFR1 does not always result in cell death. The fate of the cell, i.e., whether it survives or dies, is controlled by multiple key checkpoints (Vanden Berghe et al., 2015). When TNFR1 is activated, it recruits downstream adaptors, such as TRADD, TRAF2, RIPK1, and E3 ubiquitin ligases, and binds to cellular inhibitor of apoptosis 1 (cIAP) 1 and (cIAP2) to assemble complex-I via its DD (Dondelinger et al., 2013; Annibaldi and Meier, 2018). RIPK1 is subsequently ubiquitinated by cIAPs to form linear ubiquitins (Annibaldi and Meier, 2018). Then, these ubiquitin chains act as a signaling scaffold to recruit the kinase complex transforming growth factor (TGF)- $\beta$-activated kinase 1 (TAK1)/TGF- $\beta$ activated kinase 1 binding protein (TAB) $2 / \mathrm{TAB} 3 / \mathrm{I} \kappa \mathrm{B}$ kinase (IKK) after $\mathrm{TNF} \alpha$ stimulation (Jaco et al., 2017; Annibaldi and Meier, 2018). The dissociation of RIPK1 from complex-I to assemble complex-II and its combination with the downstream adaptor protein FADD

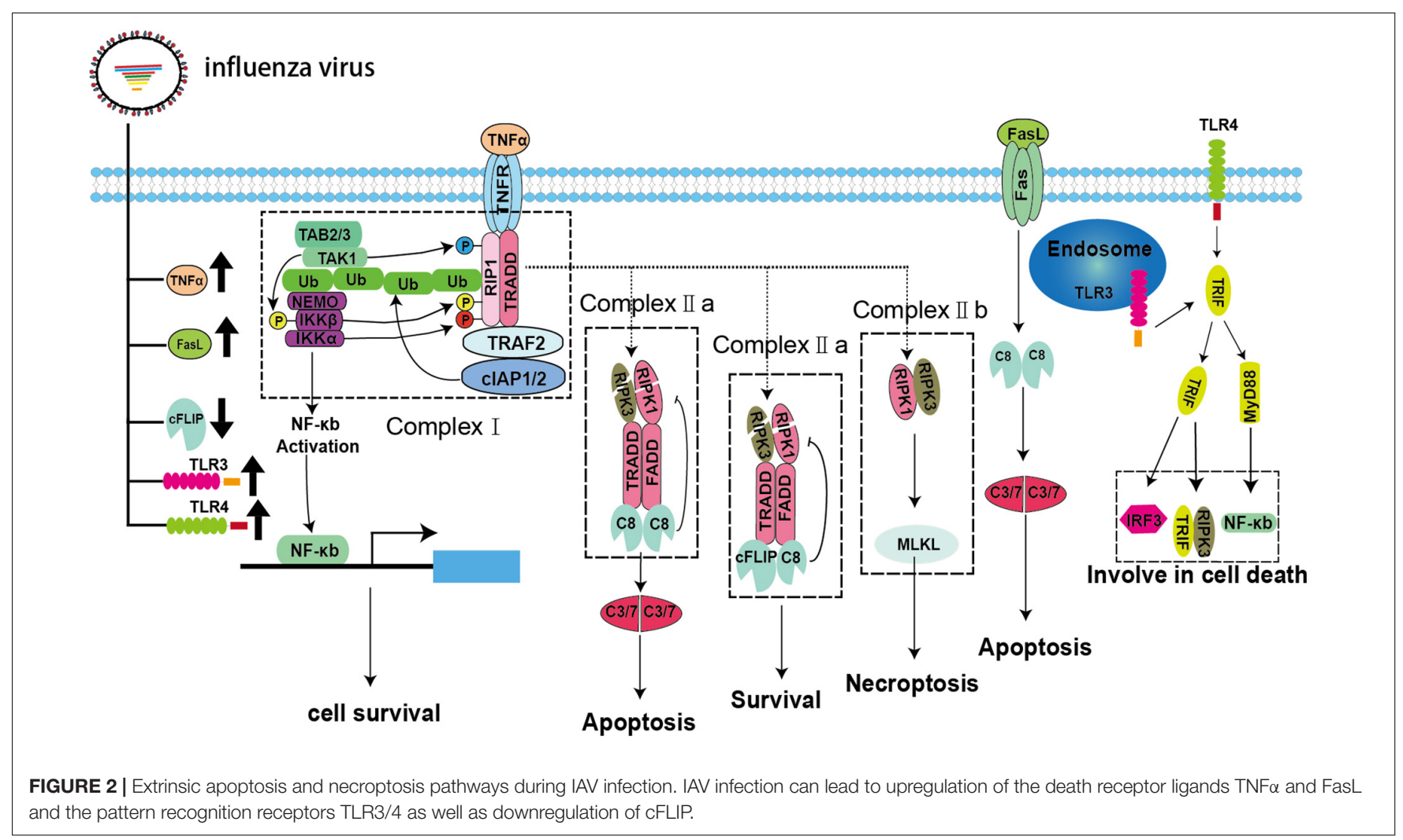


and pro-caspase- 8 are dependent on some vital checkpoints (Annibaldi and Meier, 2018). In complex-I, RIPK1 is directly phosphorylated by TAK1/IKK $\alpha / \mathrm{IKK} \beta$ to inhibit complex-II formation and apoptosis (Dondelinger et al., 2015; Annibaldi and Meier, 2018). In addition, MK2 and nuclear factor (NF)$\kappa \mathrm{B}$ can also be activated by TAK1 and IKK, respectively, resulting in the phosphorylation of cytoplasmic RIPK1, thereby, impairing complex-II assembly and the production of prosurvival molecules, such as cellular FADD-like interleukin (IL)$1 \beta$-converting enzyme-inhibitory protein (cFLIP), to inhibit the activation of caspase-8 (Dondelinger et al., 2017; Jaco et al., 2017; Annibaldi and Meier, 2018). However, little is known about the strategies developed by IAVs to modulate extrinsic apoptosis. Fortunately, IAV infection may upregulate pro-apoptotic TNF $\alpha$ and FasL and downregulate anti-apoptotic cFLIP in vivo and in vitro; therefore, we speculate that IAVs can mediate apoptosis via TNF $\alpha$, FasL, and cFLIP (Figure 2; Herold et al., 2008; Monteerarat et al., 2010). Additionally, influenza viruses that use other strategies to manipulate extrinsic apoptosis cannot be excluded.

\section{NECROPTOSIS DURING INFLUENZA A VIRUS INFECTION}

Necroptosis is a newly identified mode of programmed cell death that can be triggered in multiple ways. Based on the molecular events involved, necroptosis can be divided into canonical and non-canonical pathways and is intimately associated with apoptosis through RIPK1 in the canonical pathway (Green and Llambi, 2015). In this pathway, RIPK1, TRADD, and FADD recruit different types of downstream adaptor proteins and assemble into a dynamic complex called complex-IIa after de-ubiquitination, checkpoint escape, and dissociation from complex-I. Complex-IIa determines the ultimate fate of the cell. The homodimer of pro-caspase- 8 is recruited to form complex-IIa, which activates pro-caspase-8, thereby inducing apoptosis (Green and Llambi, 2015). Typically, cFLIP, which is a structural analog of pro-caspase-8, recruits complex-IIa to form heterodimers with pro-caspase- 8 and prevent its activation (Green and Llambi, 2015). As shown in Figure 2, both procaspase-8 homodimer and pro-caspase-8/cFLIP heterodimer can cleave essential necrosis modulators, such as RIPK1 and RIPK3. Thus, pro-caspase-8/cFLIP heterodimer can inhibit both apoptosis and necroptosis (Green and Llambi, 2015). However, when the function of either caspase- 8 or cFLIP is suppressed, RIPK1 and RIPK3 forms an amyloid-like, intracellular complex$\mathrm{IIb}$ (necrosome) to transmit the necroptosis signal through the downstream protein MLKL. MLKL is a pseudokinase that is phosphorylated and transferred to the cellular membrane after forming oligomers. Then, a pore is formed on the cellular membrane, which can lead to leakage of intracellular contents and induce necroptosis (Green and Llambi, 2015). However, the extent to which IAV is involved in this process is unclear. To date, only NS1 has been shown to interact with MLKL and induce its oligomerization, followed by disruption of the cell membranes (Figure 1; Gaba et al., 2019). Toll-like receptor (TLR) 3/4-mediated necroptosis is another non-canonical pathway that involves the downstream adaptor TIR-domain-containing adapter-inducing IFN- $\beta$ (TRIF), which contains a C-terminal RHIM motif, and recruit RIPK3 to participate in necroptosis ( $\mathrm{He}$ et al., 2011; Tsai et al., 2014). In fact, TLR3/4 are significantly upregulated in vivo and in vitro during IAV infection, and MyD88 and TRIF can be recruited to activate the downstream signaling molecules IFN regulatory factor 3 and NF- $\kappa \mathrm{B}$, which are closely related to inflammation and cell death (Figure 2; Le Goffic et al., 2007; He et al., 2011; Matsumoto et al., 2011; Tsai et al., 2014, 2015; Ma et al., 2020; Bertheloot et al., 2021). Current studies have suggested that IAV may trigger necroptosis through the TLR3/4/TRIF pathway, although direct evidence for IAV-induced necroptosis through this axis is lacking (Figure 2; Le Goffic et al., 2007; He et al., 2011; Matsumoto et al., 2011; Tsai et al., 2014, 2015).

In addition to its roles in apoptosis, DAI has also been associated with necroptosis. vRNPs are sensed by DAI, which then recruits the downstream protein RIPK3 and activates MLKL to induce necroptosis (Kuriakose et al., 2016; Thapa et al., 2016; Kesavardhana et al., 2017). Necrosomes and the phosphorylated form of $\mathrm{MLKL}$ in $\mathrm{DAI}^{-/-}$murine embryo fibroblasts or LET1 cells were undetected after IAV infection (Thapa et al., 2016). However, when $\mathrm{MLKL}^{-/-}$murine bone marrow-derived macrophages (BMDMs) were infected with IAV, the activated forms of caspase- 1 and caspase- 8 were detected (Kuriakose et al., 2016). Furthermore, cell death in $\mathrm{MLKL}^{-/-}$BMDMs showed no difference compared with that in WT BMDMs (Kuriakose et al., 2016). Intriguingly, a broad spectrum caspase inhibitor, Z-VADFMK, prevented cell death in $\mathrm{MLKL}^{-/-}$BMDMs (Kuriakose et al., 2016). These results demonstrated that multiple cell death pathways, including necroptosis, could be activated in IAVinfected cells. Moreover, the HA protein of seasonal IAV seems to be involved in necroptosis (Hartmann et al., 2017). However, the underlying mechanism has not yet been elucidated (Table 1 and Figure 1).

\section{PYROPTOSIS DURING INFLUENZA A VIRUS INFECTION}

For many years, pyroptosis was regarded as a caspase-1 mediated cell death mechanism in monocytes infected with bacteria, and caspase- 1 was considered the executioner of pyroptosis (Shi et al., 2017). However, caspase-1 is now considered to a downstream product of inflammasomes, including AIM2/ASC, NLRC4, NLRP3/ASC, Pyrin/ASC, and NLRP1. The real pyroptosis executioner is gasdermin D (GSDMD). GSDMD is cleaved by caspase-1, which leads to exposure of the N domain of GSDMD and pore formation, thereby inducing pyroptosis (Ding et al., 2016). In an addition to caspase- 1 , caspases- $4,-5,-8$, and -11 have been shown to cleave GSDMD and trigger pyroptosis directly via a non-canonical pathway (Shi et al., 2014, 2017; Orning et al., 2018).

Pyroptosis has also been observed during IAV infection. Indeed, PB1-F2 from PR8 and H7N9 viruses was shown to induce ASC speck formation, NLRP3 activation, and IL-1 $\beta$ 
secretion (Pinar et al., 2017). These results are consistent with previous studies (Figure 3; McAuley et al., 2013). The influenza virus M2 protein was found to activate inflammasome and induce pyroptosis by modifying intracellular $\mathrm{pH}$ (Figure 3; Ichinohe et al., 2010). Several studies have indicated that DAI is also involved in the regulation of pyroptosis during IAV infection (Kuriakose et al., 2016; Thapa et al., 2016). A previous study demonstrated that DAI recognize vRNPs and triggers pyroptosis during IAV infection. Moreover, in $\mathrm{DAI}^{-/-}$or
RIPK $3^{-/-}$caspase- $8^{-/-}$BMDMs, the active form of caspase- 1 is completely abolished. Even in RIPK3 ${ }^{-/-}$BMDMs, the activation of caspase- 1 is extremely reduced compared with that in WT BMDMs. IL-1 $\beta$ and IL-18 are also significantly downregulated (Kuriakose et al., 2016). These results indicate that RIPK3caspase- 8 is located upstream of GSDMD and downstream of DAI; however, it is not clear how the DAI-RIPK3-caspase-8 signal induces pyroptosis. Nevertheless, GSDMD is cleaved by caspase-8 (Orning et al., 2018; Sarhan et al., 2018) and the

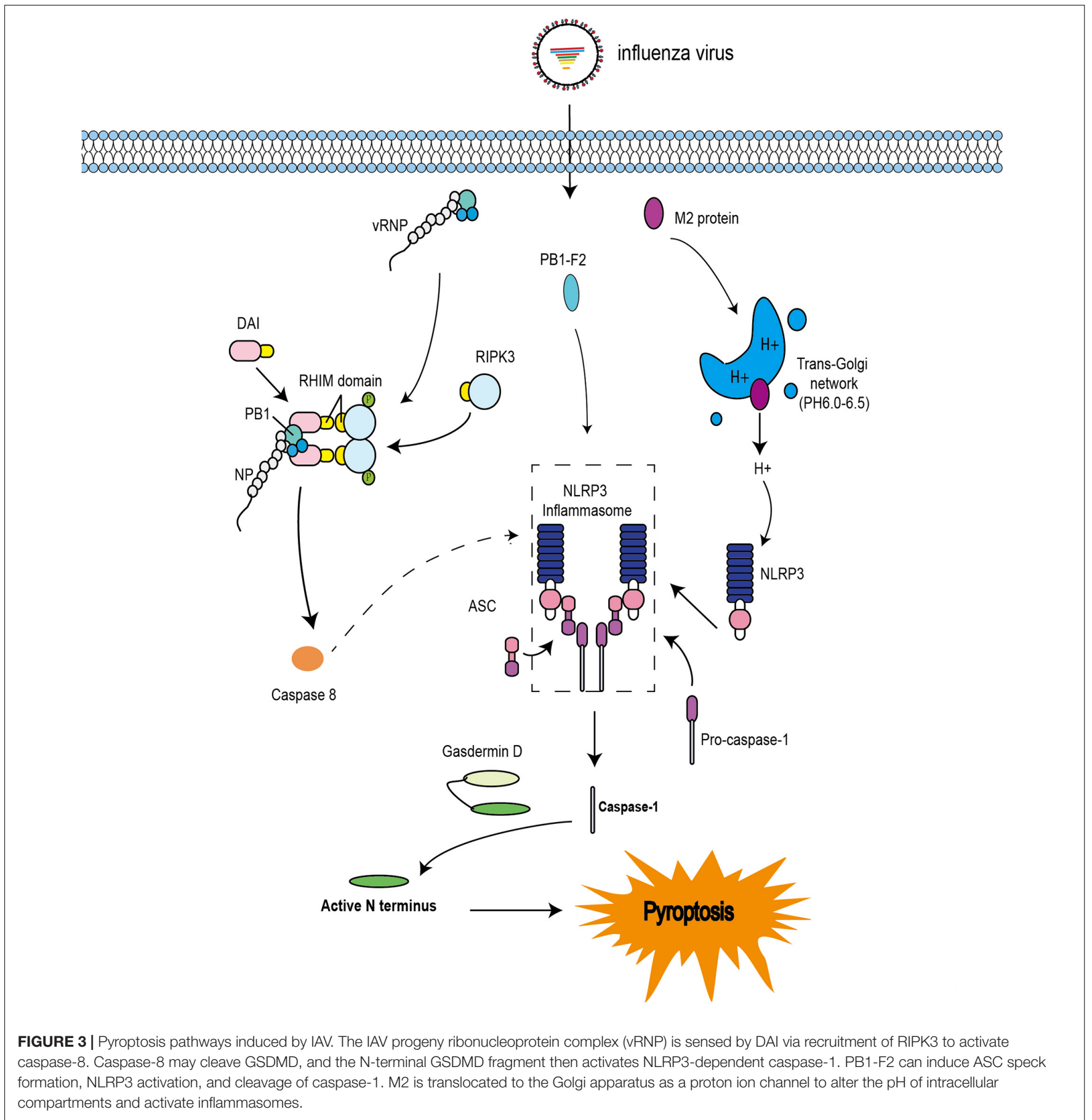


$\mathrm{N}$-terminal GSDMD fragment, which is the active form of GSDMD, triggers the activation of NLRP3-dependent caspase1 via non-canonical inflammasome signaling (Kayagaki et al., 2015). Based on these studies, IAV infection may trigger pyroptosis via the RIPK1-RIPK3-caspase-8-GSDMD axis and then induce inflammation, leading to pyroptosis via the NLRP3dependent caspase-1 activation signal (Figure 3).

Cell death is a vital part of the immune response against viral infection, and can suppress virus replication. However, excessive cell death may induce cytokine storms, thereby worsening the disease. This contradictory phenomenon has been observed in previous studies (Kuriakose et al., 2016; Thapa et al., 2016). For example, DAI is a pivotal sensor that can sense the vRNP of IAV and induce cell death (Kesavardhana et al., 2017). In a comparative analysis of $\mathrm{WT}$ and $\mathrm{DAI}^{-/-}$mice infected with the PR8 influenza strain, all WT mice recovered from viral infection within 15-18 days post-infection (Thapa et al., 2016). However, $80 \%$ of $\mathrm{DAI}^{-/-}$mice succumbed to IAV infection. Higher lung viral titers and longer recovery times were observed in $\mathrm{DAI}^{-/-}$mice compared with those in WT mice (Thapa et al., 2016). Thus, the role of DAI in IAV infection is controversial. Kuriakose et al. (2016) reported a decrease in mortality in IAVinfected $\mathrm{DAI}^{-/-}$mice, although these mice had higher lung viral titers (Kuriakose et al., 2016). Moreover, the inflammatory response and epithelial damage in IAV-infected $\mathrm{DAI}^{-/-}$mice are both reduced (Kuriakose et al., 2016), consistent with the findings of Thapa et al. (2016). However, the differences between these studies remain unexplained. Over all, the results of the animal experiments indicated that IAV-mediated cell death is decreased, whereas viral replication and inflammation responses are attenuated. Further studies are needed to assess whether these features are associated with a good prognosis.

\section{CROSS-TALK AMONG APOPTOSIS, NECROPTOSIS, AND PYROPTOSIS}

Upon infection with IAV, apoptosis, necroptosis, and pyroptosis (PANoptosis) have been observed both in vitro and in vivo (Lee et al., 2018). DAI has been found to directly recognize vRNPs and recruit an array of molecules, namely, NLRP3, RIPK1, RIPK3, caspase-8, caspase-6, and ASC, to form a multiprotein platform called PANoptosome (Christgen et al., 2020; Zheng et al., 2020). The PANoptosome initiates the cell death signal, i.e., PANoptosis. The interaction between DAI and different adaptors activates distinct forms of cell death (Kuriakose et al., 2016; Thapa et al., 2016). DAI-RIPK1-FADD-CASPASE-8 signaling pathway promotes apoptosis (Thapa et al., 2016). The DAIRIPK3-MLKL signaling pathway induces necroptosis (Thapa et al., 2016), and the DAI-NLRP3-CASPASE-1 signaling pathway triggers pyroptosis (Kuriakose et al., 2016). Although the critical initiator, DAI, is involved in PANoptosis during IAV infection, the molecular details of the formation and dissociation of the PANoptosome remain poorly understood. Furthermore, although vRNPs are recognized by DAI, it is unclear which cell death signal is activated preferentially, and the precise spatio-temporal order and the mechanisms of different cell death signaling cascades also remain unclear. Thus, further research focusing on elucidating of these mechanisms is necessary to identify novel targets for drug development.

\section{CELL DEATH AND INFLAMMATION}

Eukaryotic cells can die via several distinct biochemical pathways, which exhibit diverse physiological and morphological features (D'Arcy, 2019). Cell death plays a critical role in organism development and host defense (Barber, 2001). IAV infection commits the cell to cell death in the form of apoptosis, necroptosis, and pyroptosis (PANoptosis) (Thapa et al., 2016). Apoptotic cells preserve membrane integrity and are considered an immunologically silent form of cell death, enabling phagocytes to engulf themselves (a process called "efferocytosis") via phosphatidylserine on the apoptotic surface (Elmore, 2007; Poon et al., 2014). By contrast, the persistence of uncleared apoptotic bodies can lead to rupture of the plasma membrane, which releases a series of damage-associated molecular patterns and triggers the inflammatory response (Poon et al., 2014; Venereau et al., 2015). Thus, the efficient clearance of IAVinfected apoptotic bodies by phagocytes is crucial to prevent further exacerbation of the inflammatory response. Phagocytosis of apoptotic bodies and IAV-infected cells by macrophages was discovered in the bronchi alveolar lavage fluid and lung tissue (Atkin-Smith et al., 2018). However, necroptosis and pyroptosis are forms of pro-inflammatory cell death, and the contents of necrotic cells released into the extracellular space elevate inflammation via multiple PRRs (Kang et al., 2014; Venereau et al., 2015). By contrast, pyroptotic cells, through persistent activation and release of the pro-inflammatory cytokines IL-1 $\beta$ and IL-18, ultimately exacerbate inflammation (Kuriakose et al., 2016; Lee et al., 2018). Eventually, excessive cell death within the upper and lower respiratory tracts and lung parenchyma further exacerbates inflammation, compromises the integrity of the epithelial cell barrier, and contributes to respiratory failure (Atkin-Smith et al., 2018).

\section{CONCLUSION}

Although some in vivo animal experiments have been performed, most of the research on programmed cell death in IAV infection has been based on in vitro experiments, which do not reflect the true course of the IAV infection. Despite the limitations of these experiments, the data can be utilized to elucidate the relationships among cell death, viral replication, and inflammatory responses. For example, CLU and API5 can alleviate the pro-apoptotic effects of NP, and significantly reduce cell death and suppress viral replication (Morris et al., 2006; Mayank et al., 2015). By contrast, one study showed that although the host protein CEACAM6 promotes cell survival, it also enhances viral replication (Gaur et al., 2012). It is unclear why these in vitro cell assays have yielded paradoxical results; however, these contradictions may be related to the differences in the influenza viral strains used, infection times, and infection dosages in the testing regime. 
More scientifically rigorous methodologies must be developed to address this issue. Moreover, analyses of clinical cases may provide some insights. A recent study of fatal cases of IAV infection revealed diffuse alveolar damage and cell death, providing insights into the relationships between cell death and disease prognosis (De Jong et al., 2006). Importantly, cytokine storm has also been shown to be closely associated with cell death. In addition to cytokine storm in IAV infection, this phenomenon has also been observed in severe acute respiratory syndrome coronavirus (SARS-CoV), Middle East respiratory syndrome coronavirus (MERS-CoV), and SARS-CoV-2 infections and has been shown to be associated with disease severity and mortality (Cao, 2020; Felsenstein et al., 2020; Zhang Y. et al., 2020). Accordingly, these findings suggest that excessive cell death may cause serious severe tissue damage and hypercytokinemia. Further studies are needed to investigate the relationships among cell death, inflammatory reactions, viral replication, and disease prognosis in IAV infection.

\section{REFERENCES}

Aglietti, R. A., and Dueber, E. C. (2017). Recent insights into the molecular mechanisms underlying pyroptosis and gasdermin family functions. Trends Immunol. 38, 261-271. doi: 10.1016/j.it.2017.01.003

Annibaldi, A., and Meier, P. (2018). Checkpoints in TNF-induced cell death: implications in inflammation and cancer. Trends Immunol. 24, 49-65. doi: 10.1016/j.molmed.2017.11.002

Atkin-Smith, G. K., Duan, M., Chen, W., and Poon, I. K. (2018). The induction and consequences of influenza A virus-induced cell death. Cell Death Dis. 9:1002. doi: 10.1038/s41419-018-1035-6

Barber, G. N. (2001). Host defense, viruses and apoptosis. Cell Death Dis. 8, 113-126. doi: 10.1038/sj.cdd.4400823

Bellamy, C. O., Malcomson, R. D., Harrison, D. J., and Wyllie, A. H. (1995). Cell death in health and disease: the biology and regulation of apoptosis. Semin. Cancer Biol. 6, 3-16. doi: 10.1006/scbi.1995.0002

Bertheloot, D., Latz, E., and Franklin, B. S. (2021). Necroptosis, pyroptosis and apoptosis: an intricate game of cell death. Cell Mol. Immunol. 18, 1106-1121. doi: 10.1038/s41423-020-00630-3

Brandes, M., Klauschen, F., Kuchen, S., and Germain, R. N. (2013). A systems analysis identifies a feedforward inflammatory circuit leading to lethal influenza infection. Cell 154, 197-212. doi: 10.1016/j.cell.2013.06.013

Cao, X. (2020). COVID-19: immunopathology and its implications for therapy. Nat. Rev. Immunol. 20, 269-270. doi: 10.1038/s41577-020-0308-3

Cardani, A., Boulton, A., Kim, T. S., and Braciale, T. J. (2017). Alveolar macrophages prevent lethal influenza pneumonia by inhibiting infection of type-1 alveolar epithelial cells. PLoS Pathog. 13:e1006140. doi: 10.1371/journal. ppat. 1006140

Chen, W., Calvo, P. A., Malide, D., Gibbs, J., Schubert, U., Bacik, I., et al. (2001). A novel influenza a virus mitochondrial protein that induces cell death. Nat. Med. 7, 1306-1312. doi: 10.1038/nm1201-1306

Chipuk, J. E., and Green, D. R. (2004). Cytoplasmic p53: bax and forward. Cell Cycle 3, 427-429.

Chipuk, J. E., Kuwana, T., Bouchier-Hayes, L., Droin, N. M., Newmeyer, D. D., Schuler, M., et al. (2004). Direct activation of Bax by p53 mediates mitochondrial membrane a novel influenza a virus mitochondrial protein that induces cell death. Nature medicine permeabilization and apoptosis. Science 303, 1010-1014.

Cho, Y. S., Challa, S., Moquin, D., Genga, R., Ray, T. D., Guildford, M., et al. (2009). Phosphorylation-driven assembly of the RIP1-RIP3 complex regulates programmed necrosis and virus-induced inflammation. Cell 137, 1112-1123. doi: 10.1016/j.cell.2009.05.037

Christgen, S., Zheng, M., Kesavardhana, S., Karki, R., Malireddi, R. K. S., Banoth, B., et al. (2020). Identification of the PANoptosome: a molecular platform

\section{AUTHOR CONTRIBUTIONS}

RG wrote the initial draft of the manuscript and prepared the figures. QC carefully revised and corrected the manuscript. Both authors contributed to the article and approved the submitted version.

\section{FUNDING}

This work was supported by the National Science and Technology Major Project (grant no. 2020ZX10001016).

\section{ACKNOWLEDGMENTS}

We would like to thank Editage (www.editage.cn) for English language editing.

triggering pyroptosis, apoptosis, and necroptosis (PANoptosis). Front. Cell Infect. Microbiol. 10:237. doi: 10.3389/fcimb.2020.00237

D'Arcy, M. S. (2019). Cell death: a review of the major forms of apoptosis, necrosis and autophagy. Cell Biol. Int. 43, 582-592. doi: 10.1002/cbin.11137

Danthi, P. (2016). Viruses and the diversity of cell death. Annu. Rev. Virol. 3, 533-553. doi: 10.1146/annurev-virology-110615-042435

De Jong, M. D., Simmons, C. P., Thanh, T. T., Hien, V. M., Smith, G. J., Chau, T. N. B., et al. (2006). Fatal outcome of human influenza A (H5N1) is associated with high viral load and hypercytokinemia. Nat. Med. 12, 1203-1207. doi: $10.1038 / \mathrm{nm} 1477$

DeFilippis, V. R., Alvarado, D., Sali, T., Rothenburg, S., and Früh, K. (2010). Human cytomegalovirus induces the interferon response via the DNA sensor ZBP1. J. Virol. 84, 585-598. doi: 10.1128/JVI.01748-09

Degterev, A., Huang, Z., Boyce, M., Li, Y., Jagtap, P., Mizushima, N., et al. (2005). Chemical inhibitor of nonapoptotic cell death with therapeutic potential for ischemic brain injury. Nat. Chem. Biol. 1, 112-119. doi: 10.1038/nchembio711

Ding, J., Wang, K., Liu, W., She, Y., Sun, Q., Shi, J., et al. (2016). Pore-forming activity and structural autoinhibition of the gasdermin family. Nature 535, 111-116. doi: 10.1038/nature18590

Dondelinger, Y., Aguileta, M., Goossens, V., Dubuisson, C., Grootjans, S., Dejardin, E., et al. (2013). RIPK3 contributes to TNFR1-mediated RIPK1 kinasedependent apoptosis in conditions of cIAP1/2 depletion or TAK1 kinase inhibition. Cell Death Differ. 20, 1381-1392. doi: 10.1038/cdd.2013.94

Dondelinger, Y., Delanghe, T., Rojas-Rivera, D., Priem, D., Delvaeye, T., Bruggeman, I., et al. (2017). MK2 phosphorylation of RIPK1 regulates TNFmediated cell death. Nat. Cell Biol. 19, 1237-1247. doi: 10.1038/ncb3608

Dondelinger, Y., Jouan-Lanhouet, S., Divert, T., Theatre, E., Bertin, J., Gough, P. J., et al. (2015). NF- $\kappa$ B-independent role of IKK $\alpha / \mathrm{IKK} \beta$ in preventing RIPK1 kinase-dependent apoptotic and necroptotic cell death during TNF signaling. Mol. Cell 60, 63-76. doi: 10.1016/j.molcel.2015.07.032

Doyon-Plourde, P., Fakih, I., Tadount, F., Fortin, E., and Quach, C. (2019). Impact of influenza vaccination on healthcare utilization-a systematic review. Vaccine 37, 3179-3189. doi: 10.1016/j.vaccine.2019.04.051

Elmore, S. (2007). Apoptosis: a review of programmed cell death. Toxicol. Pathol. 35, 495-516. doi: 10.1080/01926230701320337

Felsenstein, S., Herbert, J. A., McNamara, P. S., and Hedrich, C. M. (2020). COVID19: immunology and treatment options. Clin. Immunol. 215:108448. doi: 10. 1016/j.clim.2020.108448

Fesq, H., Bacher, M., Nain, M., and Gemsa, D. (1994). Programmed cell death (apoptosis) in human monocytes infected by influenza A virus. Immunobiology 190, 175-182. doi: 10.1016/S0171-2985(11)80292-5

Frabutt, D. A., Wang, B., Riaz, S., Schwartz, R. C., and Zheng, Y. H. (2018). Innate sensing of influenza a virus hemagglutinin glycoproteins by the host endoplasmic reticulum (ER) Stress pathway triggers a potent antiviral response 
via ER-associated protein degradation. J. Virol. 92, e1690-e1617. doi: 10.1128/ JVI.01690-17

Friedlander, A. M. (1986). Macrophages are sensitive to anthrax lethal toxin through an acid-dependent process. J. Biol. Chem. 261, 7123-7126.

Fuchs, Y., and Steller, H. (2011). Programmed cell death in animal development and disease. Cell 147, 742-758. doi: 10.1016/j.cell.2011.10.033

Gaba, A., Xu, F., Lu, Y., Park, H.-S., Liu, G., and Zhou, Y. (2019). The NS1 protein of influenza A virus participates in necroptosis by interacting with MLKL and increasing its oligomerization and membrane translocation. J. Virol. 93, e1835-e1818. doi: 10.1128/JVI.01835-18

Galluzzi, L., Brenner, C., Morselli, E., Touat, Z., and Kroemer, G. (2008). Viral control of mitochondrial apoptosis. PLoS Pathog. 4:e1000018. doi: 10.1371/ journal.ppat.1000018

Gannage, M., Dormann, D., Albrecht, R., Dengjel, J., Torossi, T., Ramer, P. C., et al. (2009). Matrix protein 2 of influenza A virus blocks autophagosome fusion with lysosomes. Cell Host Microbe 6, 367-380. doi: 10.1016/j.chom.2009.09.005

Gao, Y. L., Zhai, J. H., and Chai, Y. F. (2018). Recent advances in the molecular mechanisms underlying pyroptosis in sepsis. Mediators Inflamm. 2018:5823823. doi: 10.1155/2018/5823823

Gaur, P., Ranjan, P., Sharma, S., Patel, J. R., Bowzard, J. B., Rahman, S. K., et al. (2012). Influenza A virus neuraminidase protein enhances cell survival through interaction with carcinoembryonic antigen-related cell adhesion molecule 6 (CEACAM6) protein. J. Biol. Chem. 287, 15109-15117. doi: 10.1074/jbc.M111. 328070

Gibbs, J. S., Malide, D., Hornung, F., Bennink, J. R., and Yewdell, J. W. (2003). The influenza A virus PB1-F2 protein targets the inner mitochondrial membrane via a predicted basic amphipathic helix that disrupts mitochondrial function. J. Virol. 77, 7214-7224. doi: 10.1128/jvi.77.13.7214-7224.2003

Green, D. R., and Llambi, F. (2015). Cell death signaling. Cold Spring Harb. Perspect. Biol. 7:a006080. doi: 10.1101/cshperspect.a006080

Guo, J., Huang, F., Liu, J., Chen, Y., Wang, W., Cao, B., et al. (2015). The serum profile of hypercytokinemia factors identified in $\mathrm{H} 7 \mathrm{n} 9$-infected patients can predict fatal outcomes. Sci. Rep. 5:10942. doi: 10.1038/srep10942

Halder, U., Bagchi, P., Chattopadhyay, S., Dutta, D., and Chawla-Sarkar, M. (2011). Cell death regulation during influenza A virus infection by matrix (M1) protein: a model of viral control over the cellular survival pathway. Cell Death Dis. 2, e197-e197. doi: 10.1038/cddis.2011.75

Hartmann, B. M., Albrecht, R. A., Zaslavsky, E., Nudelman, G., Pincas, H., Marjanovic, N., et al. (2017). Pandemic H1N1 influenza A viruses suppress immunogenic RIPK3-driven dendritic cell death. Nat. Commun. 8:1931. doi: 10.1038/s41467-017-02035-9

He, S., Liang, Y., Shao, F., and Wang, X. (2011). Toll-like receptors activate programmed necrosis in macrophages through a receptor-interacting kinase3-mediated pathway. Proc. Natl. Acad. Sci. U.S.A. 108, 20054-20059. doi: 10. 1073/pnas.1116302108

He, S., Wang, L., Miao, L., Wang, T., Du, F., Zhao, L., et al. (2009). Receptor interacting protein kinase-3 determines cellular necrotic response to TNFalpha. Cell 137, 1100-1111. doi: 10.1016/j.cell.2009.05.021

Henson, P. M., Bratton, D. L., and Fadok, V. A. (2001). Apoptotic cell removal. Curr. Biol. 11, R795-R805. doi: 10.1016/s0960-9822(01)00474-2

Herold, S., Steinmueller, M., von Wulffen, W., Cakarova, L., Pinto, R., Pleschka, S., et al. (2008). Lung epithelial apoptosis in influenza virus pneumonia: the role of macrophage-expressed TNF-related apoptosis-inducing ligand. J. Exp. Med. 205, 3065-3077. doi: 10.1084/jem.20080201

Hinshaw, V. S., Olsen, C. W., Dybdahl-Sissoko, N., and Evans, D. (1994). Apoptosis: a mechanism of cell killing by influenza A and B viruses. J. Virol. 68, 3667-3673. doi: 10.1128/JVI.68.6.3667-3673.1994

Holler, N., Zaru, R., Micheau, O., Thome, M., Attinger, A., Valitutti, S., et al. (2000). Fas triggers an alternative, caspase-8-independent cell death pathway using the kinase RIP as effector molecule. Nat. Immunol. 1, 489-495. doi: 10.1038/ 82732

Ichinohe, T., Pang, I. K., and Iwasaki, A. (2010). Influenza virus activates inflammasomes via its intracellular M2 ion channel. Nat. Immunol. 11:404. doi: 10.1038/ni.1861

Jaco, I., Annibaldi, A., Lalaoui, N., Wilson, R., Tenev, T., Laurien, L., et al. (2017). MK2 phosphorylates RIPK1 to prevent TNF-induced cell death. Mol. Cell 66, 698.-710. doi: 10.1016/j.molcel.2017.05.003
Jorgensen, I., Rayamajhi, M., and Miao, E. A. (2017). Programmed cell death as a defence against infection. Nat. Rev. Immunol. 17, 151-164. doi: 10.1038/nri. 2016.147

Kang, R., Lotze, M. T., Zeh, H. J., Billiar, T. R., and Tang, D. (2014). Cell death and DAMPs in acute pancreatitis. Mol. Med. 20, 466-477. doi: 10.2119/molmed. 2014.00117

Kayagaki, N., Stowe, I. B., Lee, B. L., O’Rourke, K., Anderson, K., Warming, S., et al. (2015). Caspase-11 cleaves gasdermin D for non-canonical inflammasome signalling. Nature 526, 666-671. doi: 10.1038/nature15541

Kerr, J. F. R., Wyllie, A. H., and Currie, A. R. (1972). Apoptosis: a basic biological phenomenon with wideranging implications in tissue kinetics. Br. J. Cancer 26, 239-257. doi: 10.1038/bjc.1972.33

Kesavardhana, S., Kuriakose, T., Guy, C. S., Samir, P., Malireddi, R. S., Mishra, A., et al. (2017). ZBP1/DAI ubiquitination and sensing of influenza vRNPs activate programmed cell death. J. Exp. Med. 214, 2217-2229. doi: 10.1084/jem. 20170550

Yamauchi, Y. (2020). Influenza A virus uncoating. Adv. Virus Res. 2020, 1-38. doi: 10.1016/bs.aivir.2020.01.001

Kuriakose, T., Man, S. M., Subbarao Malireddi, R. K., Karki, R., Kesavardhana, S., Place, D. E., et al. (2016). ZBP1/DAI is an innate sensor of influenza virus triggering the NLRP3 inflammasome and programmed cell death pathways. Sci. Immunol. 1:aag2045. doi: 10.1126/sciimmunol.aag2045

Lam, W. Y., Tang, J. W., Yeung, A. C. M., Chiu, L. C. M., Sung, J. J. Y., and Chan, P. K. S. (2008). Avian influenza virus A/HK/483/97(H5N1) NS1 protein induces apoptosis in human airway epithelial cells. J. Virol. 82, 2741-2751. doi: 10.1128/JVI.01712-07

Le Goffic, R., Pothlichet, J., Vitour, D., Fujita, T., Meurs, E., Chignard, M., et al. (2007). Cutting edge: influenza a virus activates TLR3-dependent inflammatory and RIG-I-dependent antiviral responses in human lung epithelial cells. J. Immunol. 178, 3368-3372. doi: 10.4049/jimmunol.178.6.3368

Lee, E.-W., Seo, J.-H., Jeong, M.-H., Lee, S.-S., and Song, J.-W. (2012). The roles of FADD in extrinsic apoptosis and necroptosis. BMB Rep. 45, 496-508. doi: 10.5483/bmbrep.2012.45.9.186

Lee, S., Hirohama, M., Noguchi, M., Nagata, K., and Kawaguchi, A. (2018). Influenza A virus infection triggers pyroptosis and apoptosis of respiratory epithelial cells through the type I interferon signaling pathway in a mutually exclusive manner. J. Virol. 92:14. doi: 10.1128/JVI.00396-18

Li, P., Nijhawan, D., Budihardjo, I., Srinivasula, S. M., Ahmad, M., Alnemri, E. S., et al. (1997). Cytochrome $c$ and dATP-dependent formation of Apaf1/caspase-9 complex initiates an apoptotic protease cascade. Cell 91, 479-489. doi: 10.1016/s0092-8674(00)80434-1

Liu, X., Kim, C. N., Yang, J., Jemmerson, R., and Wang, X. (1996). Induction of apoptotic program in cell-free extracts: requirement for dATP and cytochrome c. Cell 86, 147-157. doi: 10.1016/s0092-8674(00)80085-9

Liu, X., Zhang, Z., Ruan, J., Pan, Y., Magupalli, V. G., Wu, H., et al. (2016). Inflammasome-activated gasdermin $\mathrm{D}$ causes pyroptosis by forming membrane pores. Nature 535, 153-158. doi: 10.1038/nature18629

Lowy, R. J. (2003). Influenza virus induction of apoptosis by intrinsic and extrinsic mechanisms. Int. Rev. Immunol. 22, 425-449. doi: 10.1080/088301803 05216

Ma, Q., Huang, W., Zhao, J., and Yang, Z. (2020). Liu Shen Wan inhibits influenza a virus and excessive virus-induced inflammatory response via suppression of TLR4/NF-кB signaling pathway in vitro and in vivo. J. Ethnopharmacol. 252:112584. doi: 10.1016/j.jep.2020.112584

MacFarlane, M., Kohlhaas, S. L., Sutcliffe, M. J., Dyer, M. J., and Cohen, G. M. (2005). TRAIL receptor-selective mutants signal to apoptosis via TRAIL-R1 in primary lymphoid malignancies. Cancer Res. 65, 11265-11270. doi: 10.1158/ 0008-5472.CAN-05-2801

Maiuri, M. C., Galluzzi, L., Morselli, E., Kepp, O., Malik, S. A., and Kroemer, G. (2010). Autophagy regulation by p53. Curr. Opin. Cell Biol. 22, 181-185. doi: 10.1016/j.ceb.2009.12.001

Matsumoto, M., Oshiumi, H., and Seya, T. (2011). Antiviral responses induced by the TLR3 pathway. Rev. Med. Virol. 21, 67-77. doi: 10.1002/rmv.680

Mayank, A., Sharma, S., Nailwal, H., and Lal, S. (2015). Nucleoprotein of influenza A virus negatively impacts antiapoptotic protein API5 to enhance E2F1dependent apoptosis and virus replication. Cell Death Dis. 6:e2018. doi: 10.1038/ cddis. 2015.360 
McAuley, J. L., Tate, M. D., MacKenzie-Kludas, C. J., Pinar, A., Zeng, W., Stutz, A., et al. (2013). Activation of the NLRP3 inflammasome by IAV virulence protein PB1-F2 contributes to severe pathophysiology and disease. PLoS Pathog. 9:e1003392. doi: 10.1371/journal.ppat.1003392

McCurrach, M. E., Connor, T. M., Knudson, C. M., Korsmeyer, S. J., and Lowe, S. W. (1997). Bax-deficiency promotes drug resistance and oncogenic transformation by attenuating p53-dependent apoptosis. Proc. Natl. Acad. Sci. U.S.A. 94, 2345-2349. doi: 10.1073/pnas.94.6.2345

Monteerarat, Y., Sakabe, S., Ngamurulert, S., Srichatraphimuk, S., Jiamtom, W., Chaichuen, K., et al. (2010). Induction of TNF- $\alpha$ in human macrophages by avian and human influenza viruses. Arch. Virol. 155, 1273-1279. doi: 10.1007/ s00705-010-0716-y

Mori, I., Komatsu, T., Takeuchi, K., Nakakuki, K., Sudo, M., and Kimura, Y. (1995). In vivo induction of apoptosis by influenza virus. J. Gen. Virol. 76, 2869-2873. doi: 10.1099/0022-1317-76-11-2869

Morris, E. J., Michaud, W. A., Ji, J.-Y., Moon, N.-S., Rocco, J. W., and Dyson, N. J. (2006). Functional identification of Api5 as a suppressor of E2F-dependent apoptosis in vivo. PLoS Genet. 2:e196. doi: 10.1371/journal.pgen.0020196

Murphy, J. M., Czabotar, P. E., Hildebrand, J. M., Lucet, I. S., Zhang, J. G., AlvarezDiaz, S., et al. (2013). The pseudokinase MLKL mediates necroptosis via a molecular switch mechanism. Immunity 39, 443-453. doi: 10.1016/j.immuni. 2013.06.018

Nagata, S. (1999). Fas ligand-induced apoptosis. Annu. Rev. Genet. 33, 29-55. doi: 10.1146/annurev.genet.33.1.29

Nailwal, H., Sharma, S., Mayank, A., and Lal, S. (2015). The nucleoprotein of influenza A virus induces p53 signaling and apoptosis via attenuation of host ubiquitin ligase RNF43. Cell Death Dis. 6:e1768. doi: 10.1038/cddis.20 15.131

Nair, P., Lu, M., Petersen, S., and Ashkenazi, A. (2014). Apoptosis initiation through the cell-extrinsic pathway. Methods Enzymol. 544, 99-128. doi: 10. 1016/B978-0-12-417158-9.00005-4

Ohtsuka, T., Ryu, H., Minamishima, Y. A., Macip, S., Sagara, J., Nakayama, K. I., et al. (2004). ASC is a Bax adaptor and regulates the p53-Bax mitochondrial apoptosis pathway. Nat. Cell Biol. 6, 121-128. doi: 10.1038/ncb1087

Orning, P., Weng, D., Starheim, K., Ratner, D., Best, Z., Lee, B., et al. (2018). Pathogen blockade of TAK1 triggers caspase-8-dependent cleavage of gasdermin D and cell death. Science 362, 1064-1069. doi: 10.1126/science. aau 2818

Pinar, A., Dowling, J. K., Bitto, N. J., Robertson, A. A., Latz, E., Stewart, C. R., et al. (2017). PB1-F2 peptide derived from avian influenza A virus H7N9 induces inflammation via activation of the NLRP3 inflammasome. J. Biol. Chem. 292, 826-836. doi: 10.1074/jbc.M116.756379

Poon, I. K., Lucas, C. D., Rossi, A. G., and Ravichandran, K. S. (2014). Apoptotic cell clearance: basic biology and therapeutic potential. Nat. Rev. Immunol. 14, 166-180. doi: 10.1038/nri3607

Rebsamen, M., Heinz, L. X., Meylan, E., Michallet, M. C., Schroder, K., Hofmann, K., et al. (2009). DAI/ZBP1 recruits RIP1 and RIP3 through RIP homotypic interaction motifs to activate NF-кB. EMBO Rep. 10, 916-922. doi: 10.1038/ embor.2009.109

Roberson, E. C., Tully, J. E., Guala, A. S., Reiss, J. N., Godburn, K. E., Pociask, D. A., et al. (2012). Influenza induces endoplasmic reticulum stress, caspase12-dependent apoptosis, and c-Jun N-terminal kinase-mediated transforming growth factor-beta release in lung epithelial cells. Am. J. Respir. Cell Mol. Biol. 46, 573-581. doi: 10.1165/rcmb.2010-04600C

Robert, G., Gastaldi, C., Puissant, A., Hamouda, A., Jacquel, A., Dufies, M., et al. (2012). The anti-apoptotic Bcl-B protein inhibits BECN1dependent autophagic cell death. Autophagy 8, 637-649. doi: 10.4161/auto. 19084

Sarhan, J., Liu, B. C., Muendlein, H. I., Li, P., Nilson, R., Tang, A. Y., et al. (2018). Caspase-8 induces cleavage of gasdermin D to elicit pyroptosis during Yersinia infection. Proc. Natl. Acad. Sci. U.S.A. 115, E10888-E10897. doi: 10.1073/pnas. 1809548115

Schultz-Cherry, S., Dybdahl-Sissoko, N., Neumann, G., Kawaoka, Y., and Hinshaw, V. S. (2001). Influenza virus ns1 protein induces apoptosis in cultured cells. J. Virol. 75, 7875-7881. doi: 10.1128/jvi.75.17.7875-7881.2001

Shi, J., Gao, W., and Shao, F. (2017). Pyroptosis: gasdermin-mediated programmed necrotic cell death. Trends Biochem. Sci. 42, 245-254. doi: 10.1016/j.tibs.2016. 10.004
Shi, J., Zhao, Y., Wang, Y., Gao, W., Ding, J., Li, P., et al. (2014). Inflammatory caspases are innate immune receptors for intracellular LPS. Nature 514, 187192. doi: 10.1038/nature13683

Slaine, P. D., Kleer, M., Duguay, B. A., Pringle, E. S., Kadijk, E., Ying, S., et al. (2021). Thiopurines activate an antiviral unfolded protein response that blocks influenza A virus glycoprotein accumulation. J. Virol. 95, e453-e421. doi: 10. 1128/JVI.00453-21

Takizawa, T., Matsukawa, S., Higuchi, Y., Nakamura, S., Nakanishi, Y., and Fukuda, R. (1993). Induction of programmed cell death (apoptosis) by influenza virus infection in tissue culture cells. J. Gen. Virol. 74, 2347-2355. doi: 10.1099/00221317-74-11-2347

Thapa, R. J., Ingram, J. P., Ragan, K. B., Nogusa, S., Boyd, D. F., Benitez, A. A., et al. (2016). DAI senses influenza A virus genomic RNA and activates RIPK3dependent cell death. Cell Host Microbe 20, 674-681. doi: 10.1016/j.chom.2016. 09.014

Tripathi, S., Batra, J., Cao, W., Sharma, K., Patel, J. R., Ranjan, P., et al. (2013). Influenza A virus nucleoprotein induces apoptosis in human airway epithelial cells: implications of a novel interaction between nucleoprotein and host protein Clusterin. Cell Death Dis. 4:e562. doi: 10.1038/cddis.2013.89

Tsai, S.-Y., Segovia, J. A., Chang, T.-H., Morris, I. R., Berton, M. T., Tessier, P. A., et al. (2014). DAMP molecule S100A9 acts as a molecular pattern to enhance inflammation during influenza A virus infection: role of DDX21-TRIF-TLR4-MyD88 pathway. PLoS Pathog. 10:e1003848. doi: 10.1371/ journal.ppat.1003848

Tsai, S.-Y., Segovia, J. A., Chang, T.-H., Shil, N. K., Pokharel, S. M., Kannan, T., et al. (2015). Regulation of TLR3 activation by S100A9. J. Immunol. 195, 4426-4437. doi: 10.4049/jimmunol.1500378

van Delft, M. F., Smith, D. P., Lahoud, M. H., Huang, D. C., and Adams, J. M. (2010). Apoptosis and non-inflammatory phagocytosis can be induced by mitochondrial damage without caspases. Cell Death Differ. 17, 821-832. doi: $10.1038 /$ cdd. 2009.166

Vanden Berghe, T., Kaiser, W. J., Bertrand, M. J., and Vandenabeele, P. (2015). Molecular crosstalk between apoptosis, necroptosis, and survival signaling. Mol. Cell. Oncol. 2:e975093. doi: 10.4161/23723556.2014.9 75093

Venereau, E., Ceriotti, C., and Bianchi, M. E. (2015). DAMPs from cell death to new life. Front. Immunol. 6:422. doi: 10.3389/fimmu.2015.00422

Wallach, D., Kang, T. B., Dillon, C. P., and Green, D. R. (2016). Programmed necrosis in inflammation: toward identification of the effector molecules. Science 352:aaf2154. doi: 10.1126/science.aaf2154

Walsh, C. M. (2014). Grand challenges in cell death and survival: apoptosis vs. necroptosis. Front. Cell Dev. Biol. 2:3. doi: 10.3389/fcell.2014.00003

Wang, Y., Hao, Q., Florence, J. M., Jung, B.-G., Kurdowska, A. K., Samten, B., et al. (2019). Influenza virus infection induces ZBP1 expression and necroptosis in mouse lungs. Front. Cell Infect. Microbiol. 9:286. doi: 10.3389/fcimb.2019. 00286

Wang, Z., Choi, M. K., Ban, T., Yanai, H., Negishi, H., Lu, Y., et al. (2008). Regulation of innate immune responses by DAI (DLM-1/ZBP1) and other DNA-sensing molecules. Proc. Natl. Acad. Sci. U.S.A. 105, 5477-5482. doi: $10.1073 /$ pnas.0801295105

Yeganeh, B., Ghavami, S., Rahim, M. N., Klonisch, T., Halayko, A. J., and Coombs, K. M. (2018). Autophagy activation is required for influenza A virus-induced apoptosis and replication. Biochim. Biophys. Acta Mol. Cell Res. 1865, 364-378. doi: 10.1016/j.bbamcr.2017.10.014

Zamarin, D., García-Sastre, A., Xiao, X., Wang, R., and Palese, P. (2005). Influenza virus $\mathrm{PB} 1-\mathrm{F} 2$ protein induces cell death through mitochondrial ANT3 and VDAC1. PLoS Pathog. 1:e4. doi: 10.1371/journal.ppat.001 0004

Zhang, D. W., Shao, J., Lin, J., Zhang, N., Lu, B. J., Lin, S. C., et al. (2009) RIP3, an energy metabolism regulator that switches TNF-induced cell death from apoptosis to necrosis. Science 325, 332-336. doi: 10.1126/science.117 2308

Zhang, T., Yin, C., Boyd, D. F., Quarato, G., Ingram, J. P., Shubina, M., et al. (2020). Influenza virus Z-RNAs Induce ZBP1-mediated necroptosis. Cell 180, 1115-1129 e1113. doi: 10.1016/j.cell.2020.02.050

Zhang, Y., Yu, L., Tang, L., Zhu, M., Jin, Y., Wang, Z., et al. (2020). A promising anti-cytokine-storm targeted therapy for COVID-19: the artificial-liver bloodpurification system. Engineering 7, 11-13. doi: 10.1016/j.eng.2020.03.006 
Zheng, M., Karki, R., Vogel, P., and Kanneganti, T. D. (2020). Caspase-6 is a key regulator of innate immunity, inflammasome activation, and host defense. Cell 181, 674.e-687.e. doi: 10.1016/j.cell.2020.03.040

Zhirnov, O. P., Konakova, T. E., Wolff, T., and Klenk, H. D. (2002). NS1 protein of influenza a virus down-regulates apoptosis. J. Virol. 76, 1617-1625. doi: 10.1128/jvi.76.4.1617-1625.2002

Zhou, X., Jiang, W., Liu, Z., Liu, S., and Liang, X. (2017). Virus infection and death receptor-mediated apoptosis. Viruses 9:316. doi: 10.3390/v9110316

Conflict of Interest: The authors declare that the research was conducted in the absence of any commercial or financial relationships that could be construed as a potential conflict of interest.
Publisher's Note: All claims expressed in this article are solely those of the authors and do not necessarily represent those of their affiliated organizations, or those of the publisher, the editors and the reviewers. Any product that may be evaluated in this article, or claim that may be made by its manufacturer, is not guaranteed or endorsed by the publisher.

Copyright (C) 2022 Gui and Chen. This is an open-access article distributed under the terms of the Creative Commons Attribution License (CC BY). The use, distribution or reproduction in other forums is permitted, provided the original author(s) and the copyright owner(s) are credited and that the original publication in this journal is cited, in accordance with accepted academic practice. No use, distribution or reproduction is permitted which does not comply with these terms. 